\title{
URBAN SOLID WASTE MANAGEMENT BY PROCESS MAPPING AND SIMULATION
}

\author{
Josiane Palma Lima*, Kelly Carla Dias Lobato, \\ Fabiano Leal and Renato da Silva Lima
}

Received August 29, 2012 / Accepted April 6, 2014

\begin{abstract}
Adequate management of urban solid waste (USW) is beneficial to the environment, cities and people who depend on the income generated from collecting this waste material to survive. Due to the level of complexity of these processes involved in recyclable USW sorting, management tools which enable systemic studies become valuable assets by evaluating the effects changes may cause on the organization. This paper presents a modeling study, which used process mapping and discrete event simulation, in which a USW collection process was evaluated. The study was conducted in conjunction with the USW trash gatherers association of Itajubá, state of Minas Gerais, Brazil. The lack of standardized processes presented difficulties for developing the simulation model. To diminish this problem, three conceptual modeling techniques were used (SIPOC, flowcharts and IDEF-SIM). Data were collected via observation, interviews and questionnaires. The validated conceptual model, obtained in this study, will be able to be used to better understand the process. Finally, the model was used to evaluate process improvement scenarios.
\end{abstract}

Keywords: Urban Solid Waste (USW), discrete event simulation, process mapping, decision making model.

\section{INTRODUCTION}

The objective of this research is to integrate mapping processes techniques with discrete event simulation. Although this integration has already been proposed in the literature, this paper aims to apply this method in sorting process for a recyclable urban solid waste (USW) gathering unit. This process has its own characteristics, which will be commented in the article, which hinder the process of modeling.

The result of this application enabled an examination of alternatives which increased the productivity of sorting process for a USW in the Association of Recyclable Materials Gatherers

*Corresponding author.

Institute of Production Engineering and Management, Federal University of Itajubá, MG, Brazil.

E-mails: jpalmalima@gmail.com; kcarladl@yahoo.com.br; fleal@unifei.edu.br; rslima@unifei.edu.br 
of Itajubá (ACIMAR). After the conceptual modeling and implementation of the computational model were carried out, scenarios were constructed and simulated possible means to improve process productivity.

In the past, urban solid waste (USW) was largely organic and, due to its quick degradation, the population's production of USW did not cause much adverse impact on the environment (Mazzer \& Cavalcante, 2004). Bari et al. (2012) comment that currently there is global concern, to find a socio, techno-economic, environmental friendly solution to sustain a cleaner and greener environment. A part of management can be done by reusing the reusable portion of the waste following excellent waste management hierarchical structures which emphasize the concepts of reduce, reuse, recycle, recover and residue. To reach the stage of recycling and reuse, the steps of sorting, collecting, processing, marketing, and ultimately making use of material that would otherwise have been thrown away.

According to Singh et al. (2011) geographical factors such as level of economic development and urban population density influences the generation of municipal waste in a country. Presence of industries within the municipal jurisdiction and level of industrialization as a whole greatly influences the quantity as quality of waste, as most of the industrial wastes from small and medium scale industries route their waste through the municipal system. Thus, adequately treating and disposing USW are necessary processes and offer many benefits, such as: improving environmental and sanitary conditions within the municipality, diminishing waste volume, saving energy and raw material and, furthermore, both directly and indirectly creating jobs by generating income from treating recyclable waste.

As to not miss out on the opportunity, in Brazil and other developing countries, organized recyclable material gatherers associations have utilized an ever increasing amount of discarded materials in order to create new products by treating and, in turn, selling them.

Recyclable materials collection associations remain economically viable by collecting the discarded material and separating it according to its type (plastic, paper, cardboard, aluminum, glass, among others) and color, which aggregates the sale price for large recycling companies. There are many challenges faced for these enterprises, among which are low productivity, which directly affects the income of those who provide the labor for the endeavor, and the absence of process improvement resources. Indirectly, the environmental benefits of recycling are reduced, putting in question the economic viability of the process in comparison with other solid waste treatment options, such as incineration or landfill usage. Increasing these associations' process efficiency, from collection to recycling, and reducing costs, is a strategic question in order to maintain recycling as the main alternative for the final destination of solid waste on a long-term scale. Recycling is treated in this study as a set of transformation techniques through chemical, biological or mechanical means, which aims to put the raw material back into the productive cycle.

Many studies have been undertaken through research and action implementation aiming to manage USW (Singh et al., 2011; Bari et al., 2012; Moreira \& Günther, 2013; Westarb Cruz et al., 2013). However, the topic's broad range and its socioeconomic and environmental importance 
lengthen the path of putting theory into practice. According to Aquino et al. (2009), in order for this to happen, investments from municipal organs in infrastructure and improving recyclable materials collection/recycling capabilities, which must meet the needs and deadlines of industrial sector enterprises, are essential for the survival of these associations.

One of the greatest hurdles for selective collection associations is increasing productivity in such a way that they are able to participate in the post-consumption productive chain. Recyclable materials gathering associations present visible problems in planning related to distribution of labor, and layout and procedural standardization, thus keeping such groups from increasing their output (Lobato \& Lima, 2010).

The process of separating recyclable material found in the study object could be described as having very loose procedures in place. This, in turn, made it more difficult to capture an accurate simulation of the system in place. Scientific literature about the subject of trash gathering associations is scant. In a search done on the database Science Direct (in September, 2013), using the words "simulation" and "trash gatherers", no articles were found. For the modeling done in this article, discrete event simulation was the chosen approach, which meets the needs of the study of refining specific information-processing behavior and related interactions inherent in simulation programming (East et al., 2009). However, due to the lack of standardization in process analysis, a greater emphasis was given to process modeling by using three distinct techniques - SIPOC, flowcharts and IDEF-SIM. Computational modeling was carried out using the simulation software ProModel ${ }^{\circledR}$.

After this brief introduction, the remainder of this article is structured as follows. Section 2 presents a review of the literature of the production chain in USW treatment. Section 3 presents the discrete event simulation theory, showing the stages of construction of simulation projects. Section 4 introduces the study's methodology. Section 5 demonstrates the scenarios generated and results analysis and, finally, in Section 7 conclusions of the study are presented.

\section{THE PRODUCTION CHAIN IN THE URBAN SOLID WASTE TREATMENT}

Within the selective collection process, USW treatment implies job creation and income for thousands of people. Nevertheless, in $42 \%$ of Brazilian cities, there are still no USW selective collection initiatives (ABRELPE, 2010) due to the cost involved for the municipalities (O'Leary $\&$ Walsh, 1999; Monteiro et al., 2001). For Tanskanen (2000) the amount of a material separately collected in an area depends on two factors: the coverage of a collection system applied and the separation activity of waste producers, consisting of participation rate and separation efficiency. The coverage of a collection system is defined as the ratio of the amount of a material produced in those properties where separate collection is available and the amount of the material in question produced in all properties of the area. Another factor that complicates recycling in Brazil is the lack of correctly dimensioned systems in relation to storage capacity and waste treatment in sorting areas (Simonetto \& Borenstein, 2006). Because this deals with businesses competing for profits, trash gatherers' associations need structures capable of efficiently managing all steps of the process and, thus, turn into sustainable enterprises. 
In spite of the cited problems, according to D'Almeida \& Vilhena (2000), a sorting and compost system, when well-operated, can diminish solid waste volume by $50 \%$, which is otherwise destined for landfills. This in turn reduces the landfill's cost of services and increases its lifespan. Productive chain sustainability is maintained when selective collection diminishes solid waste volume destined for landfills, or when USW is sent to sorting centers maintained by gatherer cooperatives, which have a much more respected job than when searching through dumpsters.

The role of the companies which contribute the discarded material sent directly to the recycling centers is presented. Many companies, even quite successful operations in direct logistics, are not capable of dealing with an efficient and effective means of Reverse Logistics (RL) (Genchev et al., 2011; Hojas Baenas et al., 2011; Oliveira et al., 2013). The growth in the number of publications on RL evidences that it is an area in development. Studies published about this topic define the scope and limits on the activities of managing inverse logistics, such as the consolidation of its concepts. In spite of presenting notable growth in the area of administrating RL and its influence on relations with distribution channels, the need for studies about the topic makes the visualization of RL systems more difficult.

On the other hand, the effective participation of recyclable materials gathering associations is one of the greatest challenges faced by such enterprises. RL in USW systems is generally composed of four steps: gatekeeping (entry), collection, sorting and disposal. According to Lambert et al. (2011), in general, the processes related to USW treatment range from the collection phases, which involves collecting the material from the street; separating and cleaning organic residue, which would be the adequate treatment of collected material; and finally disposing of the waste through recycling or compost processes; and finally are transformed into raw material and return to the productive chain.

According to Simonetto \& Borenstein (2006), in the recycling stage, the materials are transported to a sorting center where a thorough sorting of the materials is done in order to put it back on the market. The sorting units must possess industrial presses in order that the recyclable material, such as paper, cardboard, aluminum and plastic, may be baled in order to ease storage, transport and resale.

Obviously, there are many processes involved from generating the solid waste until its final destination. For the gatherers' associations, much importance is given to the processes of USW treatment, as this composes the organization's structure. Along this chain, the association's productive process consists in materials collection, box distribution, sorting, pressing and tying the bales for storage and resale. Thus, in order for the enterprise to succeed, an organization must manage its processes in an organized fashion, utilize techniques to analyze its bottlenecks and seek productivity improvement with frequent analyses of activities to identify those which do not aggregate value and may be eliminated, simplified or combined. Bottlenecks may be present in any link of the productive chain, and may be due to material causes (such as low quality production inputs or equipment), organizational causes (such as organizational structure), labor organization, or even the procedures adopted and personal motivation factors, such as salary and effort (Polaz \& Teixeira, 2009). 
The dynamic nature of bottlenecks is worth mentioning. Upon discovering a bottleneck in a productive process, decision makers should search for the cause(s) for low productivity and seek solutions for the problems located. However, after having taken care of the bottleneck problem, another activity may then turn into the new bottleneck, necessitating new studies to continue improving the system.

\section{SIMULATION PROJECTS}

Simulation, modeling and analysis of the manufacturing system to improve performance, have become increasingly important in recent decades. Modeling and simulation help visualize, assess, implement, change, and improve complex production processes by using computer animations within a reasonable time and investment. Thus, with the fierce competition among businesses, it is necessary to implement new strategies to improve company performance (Sandanayake \& Oduoza, 2009).

Simulation is a useful tool to investigate a wide variety of "what if" questions about the real world system. Potential changes to the system can first be simulated, in order to predict their impact on system performance (Banks et al., 2005). The same authors state that the model can produce valuable insight into which variables are the most important and into how variables interact.

Simulation models have become a very popular technique employed to assess complex industrial systems, according to O'Kane et al. (2000). According to Greasley (2003), Business Process Simulation (BPS) is a tool developed to assess manufacturing systems. Today, however, it is being used to help the change management in a variety of processes and services. Montevechi et al. (2007) built a flow chart in which the logic to design simulation is explained. This sequence is divided into three main phases: conception, implementation and analysis.

In the conceptual phase, the project team defines the specific objectives and the model scope. Next, the conceptual model is built with the objective of representing the current system, by making the construction of the computer simulation model easier. Some techniques that can be used in this phase are: value stream mapping which is found in Abdulmalek \& Rajgopal (2007), process mapping as referred to in Greasley (2006), flow chart, SIPOC (Suppliers/Inputs/Process/ Outputs/Customers), IDEF0 (Integrated Definition methods language 0) and IDEF-SIM (Integrated Definition methods - Simulation). Once the conceptual model has been built and validated by the process specialists, the input variables (independent) and the output variables (dependent) can be defined. After that, the input data are collected and fitted to a probability distribution that feeds the computer model. In fact, the simulation model will be trustful if the data are (Montevechi et al., 2010).

Ryan \& Heavey (2006) state that few modeling techniques used in BPM (Business Process Modeling) provide the necessary support for a simulation project. Still according to the referred authors, although there are many process mapping techniques, only a few focus on simulation projects. Considering the importance granted to the conceptual modeling of processes and the lack of conceptual modeling techniques focusing simulation, Montevechi et al. (2010) state that 
the main characteristic of IDEF-SIM technique is the similarity of its application logic with the logic used in discrete event simulation. This characteristic has as an objective the creation of a conceptual model of the process to be simulated that contains elements required in the computer modeling phase.

The elements used to compose the IDEF-SIM technique were selected from the already acclaimed modeling techniques IDEF0 and IDEF3 (Nist, 1993) and flowchart (Aguilar-Savén, 2004). Next, the role of each element is detailed:

- Entity: represent the items to be processed by the system, representing raw material, products, people and documents, among others. They can be grouped or divided during the production process and are moved alone or through resources. Once represented, the symbol will only appear at the moment when a new entity is created. This way, the number of entities to be used and in which points of the model the entity will undergo a transformation becomes clear;

- Functions: represent the places where the entity will undergo an action. Functions are understood as: work posts, conveyor belts, rows and stocks, and service posts. These functions can change an entity, such as in the service posts, or even alter the time of this entity on the flow, as a delay (rows, stock);

- Entity flow: represent the direction of the entity in the model, characterizing the moment of input and output of the entities in the functions;

- Resources: represent elements used for moving the entities and executing functions. The re-sources can represent people or equipment. In a system, there can be static or dynamic resources. The static resources are not endowed by movement. The dynamic resources, on the other hand, can move through an established path;

- Controls: represent the rules used in the functions, such as sequencing, row rules, programming, among others;

- Rules for parallel and/or alternatives flows: these rules are called junctions, in the IDEF3 technique. Two or more paths, after a function, can be executed together (junction AND), or in an alternative way (junction OR), or allowing both rules (junction AND/OR);

- Motion: represents an entity displacement, in which the modeler believes to possess an important effect on the model. When this element is represented, a specific programming for this motion, with time spent and resource used is expected to be found, in the computer model;

- Explanatory information: used to insert an explanation in the model, aiming at facilitating the understanding of the model;

- Input flow in the modeled system: defines the input or the creation of entities in the model. 
- End of system: defines the end of a path inside the modeled flow. Everything that, in practice, is found beyond this point is out of the limits of the model;

- Connection to other figure: used to divide the model into different figures.

In the implementation phase, the conceptual model is changed into a computer model through the programming in a simulator. Sundry software are available on the market for simulation use, and its main features are: (a) graphical interface for communication with users; (b) object-oriented model design; (c) animation capability; (d) ability to provide reports; and (e) use of statistical tools. The simulation software packages, e.g. Arena ${ }^{\circledR}$, AutoMode ${ }^{\circledR}$, Empower ${ }^{\circledR}$, ProModel ${ }^{\circledR}$, and Quest ${ }^{\circledR}$, contains tools to insert the input parameters that provide the desired output parameters (Appelqvist \& Lehtonen, 2003). In this paper, the ProModel ${ }^{\circledR}$ simulator was used to build and run the model.

After that, the computer model should go through two fundamental steps in a simulation study: the verification and the operational validation process (Banks et al., 2005). The verification process consists in corroborating that a conceptual model was correctly translated into the computer model. For the validation of the models, Sargent (2004) describes several techniques in the literature that can be used subjectively and objectively. "Objectively" means the use of statistical techniques or mathematical procedures, hypothesis testing, and confidence intervals. In this context, the works of Kleijnen (1995) and Leal et al. (2011) can be mentioned, which proposes a validation statistical technique based on confidence interval.

Lastly, but not less important, the analysis phase. Once the model was verified and validated, it is time to experiment inside the domain of validation. This phase is the most anticipated by the project team, and allows the computing of various performance measures (Pirard, Iassinovski \& Riane, 2011).

\section{METHODOLOGY}

This research utilizes modeling and simulation as quantitative research methods and qualitative methods for the bibliographic review and data collection. Observation, interviews and questionnaires were the means of collection, enabling the elaboration of the conceptual and computational models and the scenario studies.

The study object is the Municipal Trash Gatherers Association of Itajubá (ACIMAR), Brazil. The city is situated in the southern portion of the state Minas Gerais, $418 \mathrm{~km}$ south-southwest from the state capital of Belo Horizonte; it is considered a typical city in terms of economic distribution and infrastructure by Brazilian standards, with approximately 100,000 inhabitants and a population density of 402.7 inhabitants $/ \mathrm{km}^{2}$. In the ACIMAR municipality, the Itajubá Recyclable Materials Gatherers Association, is one of the groups responsible for selective collection and counts on support from the city's office of the Secretary of Environmental Affairs (Lobato \& Lima, 2010). 
Previous research (Lobato \& Lima, 2010) showed that in relation to the volume collected, plastic materials are the most common and are composed of green, transparent, and oil PET, taking up a great amount of space in the ACIMAR installations. However, when the number of bales produced and stored is considered, the quantity of cardboard is rather dramatic and makes up the most commonly stored material when compared to papers and plastics. However, just paper, plastic and cardboard are baled by ACIMAR.

Given that only paper, plastic and cardboard are baled by ACIMAR, Figure 1 presents data collected along with ACIMAR, comparing the amount of bales produced in each type of material, considering the first quarter of 2011.

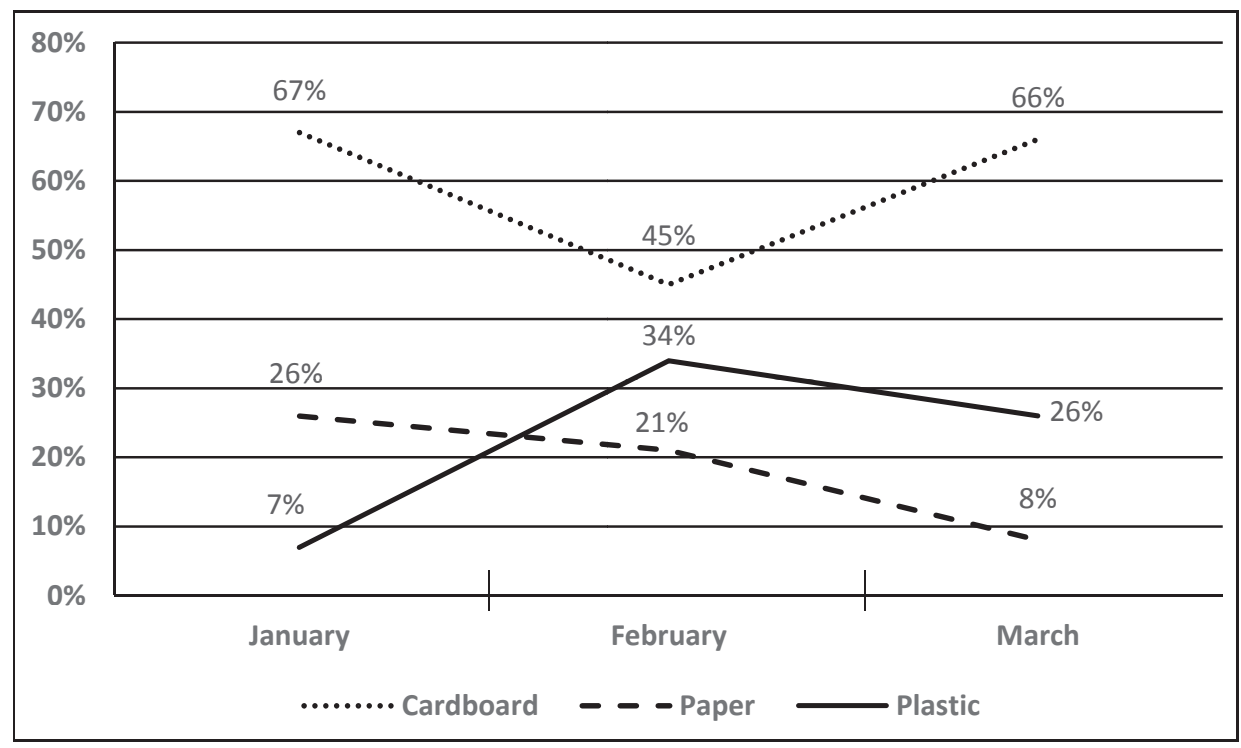

Figure 1 - Percentage of baled USW in the first quarter of 2011.

Aside from collection of material in the streets, ACIMAR counts on donations from businesses in the region. Among the received materials, cardboard and plastic are the most donated, representing $80 \%$ of all donations. The profit originating from these material donations is divided among all the associations.

\subsection{Process Characterization}

Firstly, aside from observation, a questionnaire was applied to the associates in order to clearly define the processes, inputs, outputs, suppliers and clients. All of this was done under the global perspective of the operations carried out in the shed, starting from the moment in which the collected material arrives. The responses obtained through the interviews and questionnaires allowed for the elaboration of a SIPOC analysis, which can be seen in Table 1. It can be seen through the SIPOC analysis that ACIMAR, as an organization that works in the sector of processing and resale of recyclable materials, possesses an organization structure with four main processes 
responsible for the association's productivity. The SIPOC enabled a clear visualization of the suppliers and clients involved in all of the services performed.

Table 1 - SIPOC of the processes carried out in the ACIMAR shed.

\begin{tabular}{|c|c|c|c|c|}
\hline Supplier & Input & Process & Output & Customer \\
\hline $\begin{array}{c}\text { Collection sector } \\
\text { Sorting sector }\end{array}$ & $\begin{array}{c}\text { Material collected } \\
\text { from streets, } \\
\text { donations } \\
\text { Manual labor }\end{array}$ & Sorting & $\begin{array}{c}\text { Separated } \\
\text { material }\end{array}$ & $\begin{array}{c}\text { Weighing } \\
\text { sector }\end{array}$ \\
\hline $\begin{array}{c}\text { Sorting sector } \\
\text { Weighing sector }\end{array}$ & $\begin{array}{c}\text { Separated material } \\
\text { Manual labor } \\
\text { Scale }\end{array}$ & Weighing & $\begin{array}{c}\text { Weighed } \\
\text { material }\end{array}$ & $\begin{array}{c}\text { Pressing and } \\
\text { baling sector }\end{array}$ \\
\hline $\begin{array}{c}\text { Weighing sector } \\
\text { Pressing sector }\end{array}$ & $\begin{array}{c}\text { Weighed material } \\
\text { Manual labor } \\
\text { Press }\end{array}$ & $\begin{array}{c}\text { Pressing and } \\
\text { baling }\end{array}$ & Baled material & $\begin{array}{c}\text { Outgoing } \\
\text { sector }\end{array}$ \\
\hline $\begin{array}{c}\text { Pressing and } \\
\text { Baling sector } \\
\text { Outgoing sector }\end{array}$ & $\begin{array}{c}\text { Baled material } \\
\text { Manual labor } \\
\text { Semi-truck }\end{array}$ & Outgoing & $\begin{array}{c}\text { Baled material } \\
\text { on semi-truck }\end{array}$ & $\begin{array}{c}\text { Final } \\
\text { customer }\end{array}$ \\
\hline
\end{tabular}

The sorting process receives the material collected in the street or from donations from the collection sector. The sorting sector supplies the sorting process with the necessary manual labor in order to carry out their tasks; the process' output is material separated according to its classification and whose final customer is the weighing sector. Sorting is an important stage in the process, as it is the one which aggregates the most value to the product.

In the weighing sector, manual labor and equipment is supplied from the sector itself. The sorting sector supplies the separated material (input) and its output is the baled material which goes on to the pressing and baling sector. The third process' suppliers are the weighing sector, which supplies the weighed material; the pressing and baling sector, upon completing its processes, generates the baled material which is destined for the outgoing sector. This same sector provides the manual labor and the semi-truck in order load pressed and baled material onto the vehicle from the final customer. The profile of ACIMAR's final customers is normally characterized as small USW enterprises, located in southern Minas Gerais and the state of São Paulo, which transform this raw-material into recycled products with greater aggregated value.

It is worth mentioning that the individuals who carry out these processes are many times the same, as they are able to execute multiple stages in the process. However, this is not true of the weighing and pressing processes, whose equipment requires that specially-trained and qualified individuals use the machinery. In the case of the press, an ACIMAR associate runs this post; in the case of the scale, an administrative employee is provided by the municipal government. Based on the macro-view of these processes, a second questionnaire was undertaken in order to detail all of the activities involved in the selection process of the collected waste materials. Within 
the macro selection process, there are 14 processes, 7 sub-processes and 16 specific activities. First, upon arriving at the shed, the truck pulls up with the gatherers, who deposit their bags at the entrance. Next, each gatherer heads for an area within the shed where he or she can sort through the collected material. In the sorting phase, all of the collected material is classified as either: green PET, transparent PET, oil-based PET, Tetra park, white PET, colored PET, plastics in general, electronic material, cardboard, white paper, aluminum cans, glass and metals.

Special care must be taken during the sorting process: wire must be taken out of spiral-bound white paper; plastic adhesive must be removed from cardboard; caps must be taken off of PET bottles in order to avoid accumulating air during the pressing process. After sorting through the material, it is taken to be weighed and then stored in designated areas within the shed corresponding to each type of material. During the pressing, wires are placed around the bale in order to keep the material bound while it is stocked. Finally, the baled material is stored in a corresponding place until it is dispatched, which generally happens once per month when the association's clients retrieve the purchased material. Dividing up the profits is done in accordance with what the associates call "division by productivity"; that is, the value received is divided up depending on the quantity collected. Those who collected more will receive a greater amount than those who collected less.

With the information collected, it was possible to map the activities. Figure 2 presents the map developed to evaluate the USW selection process. The map contains seven activity flows characterized by their particular activities and the necessities for each type of material. The materials represented in the map were classified as Plastic Materials (PM), Cardboard (CB), white paper (WP), Cans (C), Glass (G), Metals (M) and Electronic Materials (EM). Along with the transport symbol, there is a code specifying the material's destination and the distance covered in centimeters.

It can be noted that the activities performed reach a total of 63 operations, which are divided in: 18 operations, 26 transport operations, 9 buffer (or waiting) operations, 2 inspections and 9 storage operations. It is important for management that the greatest number of activities be classified as operations which aggregate value to the final product. However, a large number of material movements can be observed, constituting almost $40 \%$ of the total number of activities. Evaluating transport is representative for process evaluation, as movement operations can be minimized by means of a physical layout studies, thus implicating improvements in terms of productivity for the association's process.

On the other hand, the number of buffers is significant (14\% of the total number of activities), thus indicating a lack of equipment and personnel in the weighing and pressing processes. This is a problem which reflects the necessity for better work conditions, which could be offered by public or private sector organizations which collaborate with associations such as ACIMAR along with better management of the processes carried out within the shed. 


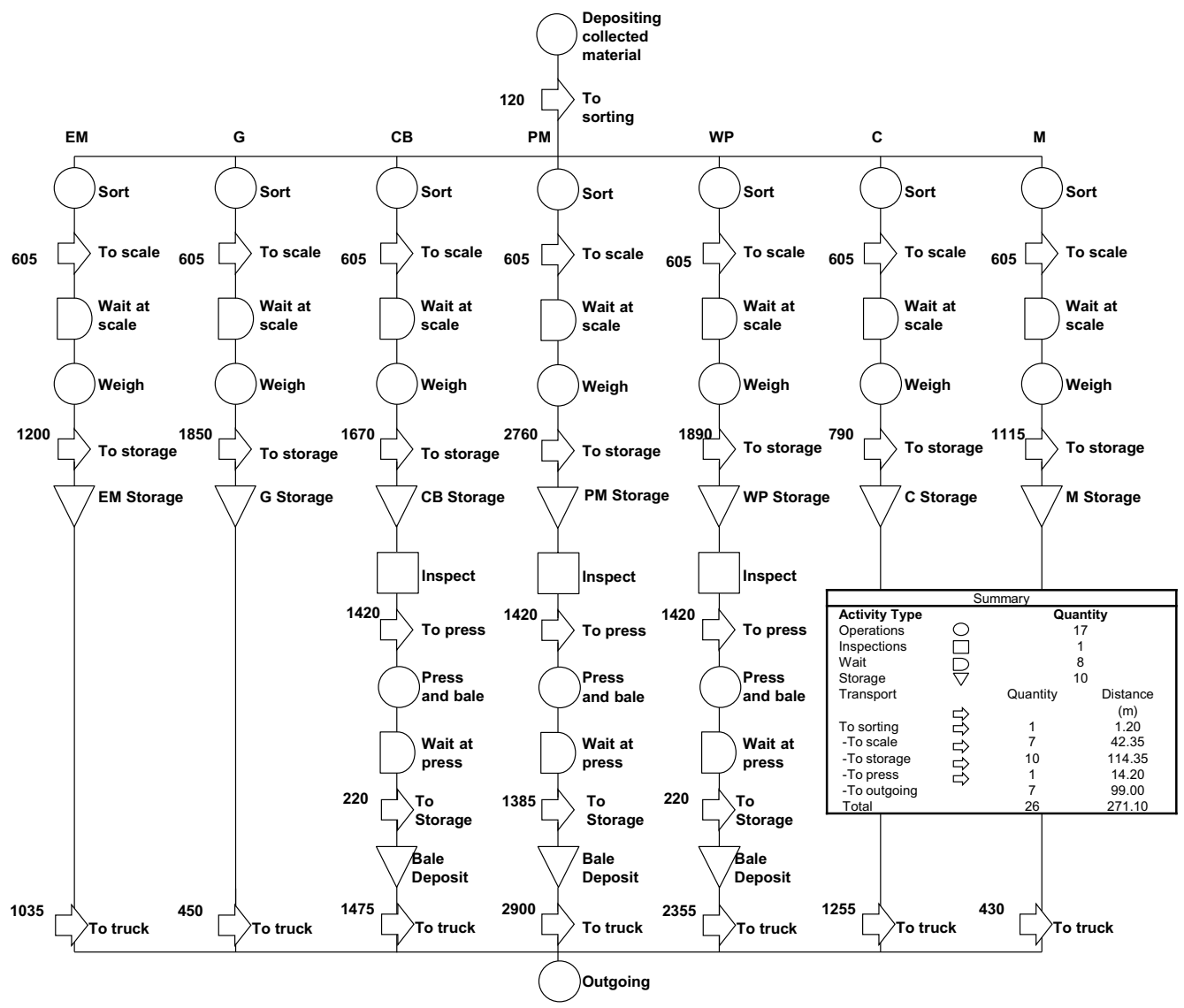

Figure 2 - Macro-process map of the ACIMAR Urban Solid Waste selection process. (Plastic Material-PM; Cardboard-CB; White paper-WP; Cans-C; Glass-G; Metals-M; Electronic Materials-EM).

\subsection{Conceptual Modeling}

The first stage of the project was to establish the project's objectives in order to orient the following steps. Thus, this project's objective was to seek alternatives for the productive system which would enable an increase in quantity of bales produced daily and increase the salaries received by the ACIMAR members.

To develop the conceptual model, the recyclable materials selection process developed by Lobato \& Lima (2010) was used as a base. The map presented seven activity flows divided by each type of material. However, the conceptual model developed using IDEF-SIM is restricted to the process of USW selection of plastic and cardboard. The model was limited to these two materials due to their importance to the entire process, as they represent the greatest contribution to the organization's profit. The mapping information served as the basis for the conceptual model which was developed using the technique IDEF-SIM, as presented in Figure 3. 
Analyzing the process via the conceptual model, one can see the productivity is limited by weighing and pressing, since the entities already separated by the conjunction "OR" (the box with the $\mathrm{X}$ ) in different routes, need to resume the single path to pass through these resources, forming lines and consequently wasting time and, thus, harming productivity.
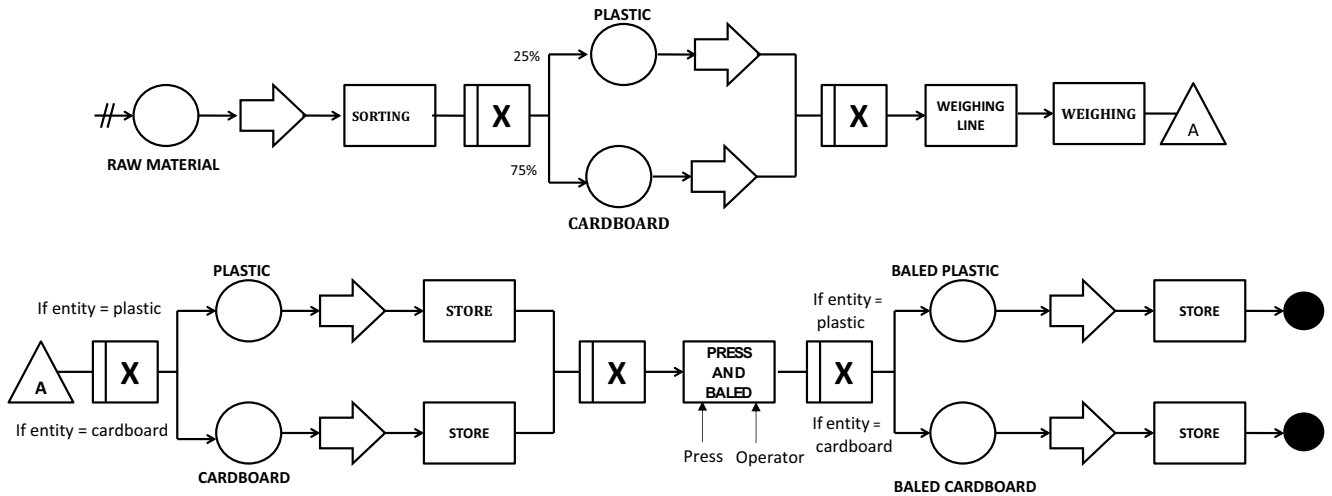

Figure 3 - Conceptual model using IDEF-SIM.

The function "Press and Baled" is carried out by a press operator. These resources were highlighted in IDEF-SIM, as they will be analyzed in possible scenarios. Table 2 presents the description of the model elements.

Table 2 - Descriptive table with model elements.

\begin{tabular}{|c|c|c|}
\hline Model elements & Quantity & Description \\
\hline Function & 8 & $\begin{array}{c}\text { Sorting (1), Weighing line (1), Weighing (1), } \\
\text { Store (4), Press and Baled (1) }\end{array}$ \\
\hline Entity & 5 & $\begin{array}{r}\text { Raw material, Plastic, Cardboard, } \\
\text { Baled Plastic, Baled Cardboard }\end{array}$ \\
\hline Arrival & 1 & Raw material \\
\hline Motion & 7 & Represented by the arrow symbol \\
\hline $\begin{array}{c}\text { Rule for } \\
\text { alternative flows }\end{array}$ & 3 & Junction OR (X) \\
\hline Resources & 2 & $\begin{array}{c}\text { Operator and Press (both are needed } \\
\text { in the function "press and baled") }\end{array}$ \\
\hline
\end{tabular}

The functions Sorting, Weighing, Press and Baled and the motions were timed and their operating times were entered into the computer model through probability distributions (stochastic). Due to little standardization process, there was a great difficulty in determining these times.

A camcorder to record the tasks performed in the process was used. This camcorder was positioned so as not to interfere in the operations. After filming, the videos were played and timed. 
For the transitions modeling between entities (Raw material, Plastic, Cardboard, Baled Plastic and Baled Cardboard) was necessary to create conversion tables between mass and number of bales. These conversion rules were obtained empirically through measurements performed on the object of study.

It was considered in the simulation the infinite availability of raw material (arrival rate). In practice this means piles of accumulated stuff, waiting for the process.

\subsection{Computational Model}

The computational model was developed using ProModel $2011^{\circledR}$. Functions were used within the parameters defined according to the process's reality, demonstrated in the input data. The input data relied on: distances and times in queues waiting for materials transportation, the measurement of stock areas and the unit capacity of each piece of equipment (scale and press).

The system entities are: raw material (material collected in bags from the streets), cardboard and plastic after sorting and cardboard and plastic bales (simulation output entities). Figure 4 shows the environment in which the simulation was developed.

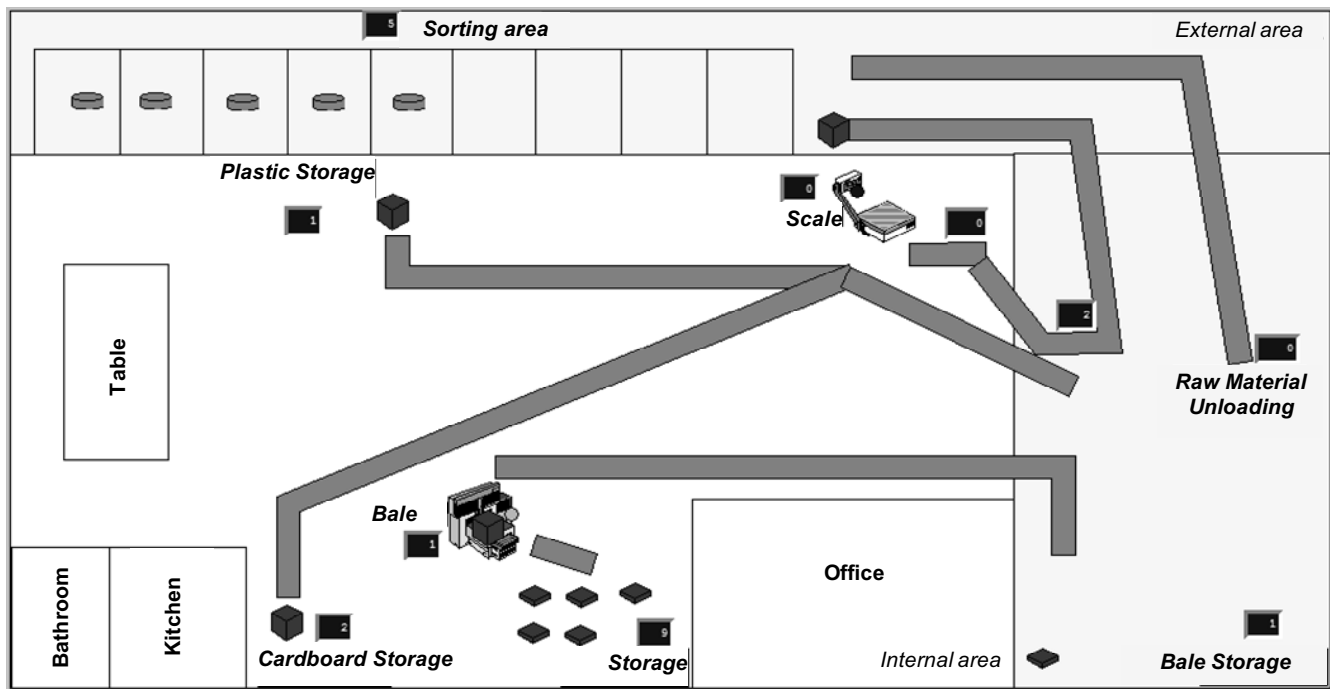

Figure 4 - Simulated Area.

The simulation was run for 10 days according to the frequency of shipments of the baled material, thus enabling the verification of the quantity of bales produced. The process's starting point is defined as the arrival of material collected from the street, being directed to the sorting activity. Each gatherer is responsible for sorting and moving the collected material, and the material donations are moved by those associates who do not take part in street collection. The process then procedes to the balance, press and baling before terminating with the baled and stocked material being ready for shipping. 
The model verification was performed through certain techniques. Visual counters were used to model, showing the result of some local variables such as the size of the queues, occupation of intermediate stocks, amount of processed entities. Monitoring the values shown in these counters allowed the researchers to eliminate some errors in the programming model. These visual indicators can be seen in Figure 4.

The graphic animation software was used as a verification tool, allowing the diagnosis of some programming errors. In addition, the software used has a verification tool (debugger), which was used by researchers.

To validate the model, the technique "face to face" was first used. In this technique, company experts viewing the animation of the simulation, found no difference between the simulated model and the real system. This technique was used for both the conceptual model and for the computational model. Company experts were gathered to monitor the development of the conceptual model and the results obtained from the simulation.

Another technique used to validate the model was proposed by Kleijnen's (1995), which consists in establishing a confidence interval for the difference between the production data from the model and the real system. If the interval contains the value zero, it can be stated with the confidence level selected, that the answers are equivalent, i.e. the simulated and the real production are equivalent. The model was validated for a confidence level of $95 \%$. It is described in (1).

The data corresponding to the quantity of bales produced daily are shown in Table 3 . The model was validated, with the zero value contained in the interval $[-1.7187 ; 3.0186]$ obtained by $(1)$.

$$
\bar{x}_{s}-\bar{x}_{r} \pm t_{2 n-2, \alpha / 2} \sqrt{\frac{S_{s}^{2}+S_{r}^{2}}{n}}
$$

where:

$x_{s}=$ mean simulation output;

$x_{r}=$ mean real output;

$S_{S}=$ standard deviation of simulated output;

$S_{r}=$ standard deviation of the real output;

$n=$ number of observations (must be the same for simulated and real);

$t_{2 n-2, \alpha / 2}=$ Student's $t$-distribution for $2 n-2$ degrees of freedom and a significance level of $\alpha / 2$.

Table 3 - Computational model validation data.

\begin{tabular}{|c|c|c|c|c|}
\hline & Average $(X)$ & Standard deviation $(s)$ & $t_{2 n-2, \alpha / 2}$ & $n$ \\
\hline Real $[r]$ & $X_{r}=6.017$ & $S_{r}=1.360$ & \multirow{2}{*}{2.776} & 3 \\
Simulated $[s]$ & $X_{S}=6.667$ & $S_{S}=0.577$ & & \\
\hline
\end{tabular}

\section{SCENARIO GENERATION}

The analysis stage deals with the development of scenarios for the verification of productive bottlenecks and proposal of process improvements. The first scenario represents reality, which 
was simulated using the computational model using time data, and information obtained from interviews and observations. Figure 5 presents the output results generated by the software.

The graph in Figure 5 emphasizes the problem verified during mapping developed in previous research (Lobato \& Lima, 2010) in which the pressing stage is a bottleneck and, therefore, the daily production of bales is limited by equipment availability. The press is in operation the entire workday. It is observed that $23 \%$ of the maximum capacity is used in sorting, coinciding with reality, since the rest of the shift is directed to material collection throughout the city. It can be seen that the storage areas used for plastic material and cardboard, before pressing (storage1_plastic and storage1_cardboard) are also occupied after the sorting due to the material collected in the street and, principally, to the donated material. As the press is not able to process this material, there is an accumulation of material in the storage area prior to baling. This scenario has a daily production of 6 bales.

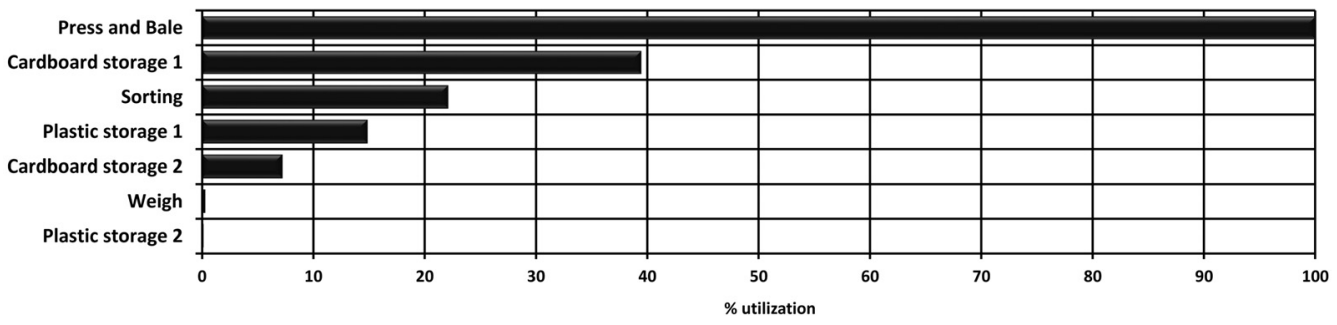

Figure 5 - Real Scenario: Model Outputs.

In the mapping, a large distance was noted inside the shed for the gatherers and associates to carry out their activities. Nonetheless, this stage does not appear as a bottleneck since the utilization percentage is low. In relation to the storage area, cardboard takes up around just $8 \%$ of the area available for this material and the area's low utilization might be an indication of poor dimensioning of the space, thus indicating a necessity for the improvement of the shed's layout. Three scenarios were simulated as described in Table 4.

Table 4 - Summary of evaluated scenarios.

\begin{tabular}{|c|c|l|}
\hline Scenarios & \multicolumn{2}{|c|}{ Description } \\
\hline Real & $\begin{array}{c}1 \text { press } \\
1 \text { operator }\end{array}$ & $\begin{array}{l}\text { Current situation: one press and one operator who feeds the equipment } \\
\text { the material, operates the press and wraps the wire around the bale }\end{array}$ \\
\hline A & $\begin{array}{c}1 \text { press } \\
2 \text { operators }\end{array}$ & $\begin{array}{l}\text { Scenario which simulates an assistant aiding the press operator, } \\
\text { helping him/her to load the press with material and in the baling phase }\end{array}$ \\
\hline B & $\begin{array}{c}2 \text { presses } \\
1 \text { operator }\end{array}$ & $\begin{array}{l}\text { Scenario that simulates the process with an additional press with a } \\
\text { single operator }\end{array}$ \\
\hline C & $\begin{array}{c}2 \text { presses } \\
2 \text { operators }\end{array}$ & $\begin{array}{l}\text { Scenario which simulates the use of two presses and two operators } \\
\text { for each }\end{array}$ \\
\hline
\end{tabular}


In scenario "A", a model was created in which two operators worked the press, thus simulating a situation in which the operator's assistant aids in loading the press with the material to be processed and wrapping the bale with wire when the pressing is finished, thus reducing the total time of operation of this equipment, as shown in Figure 6.

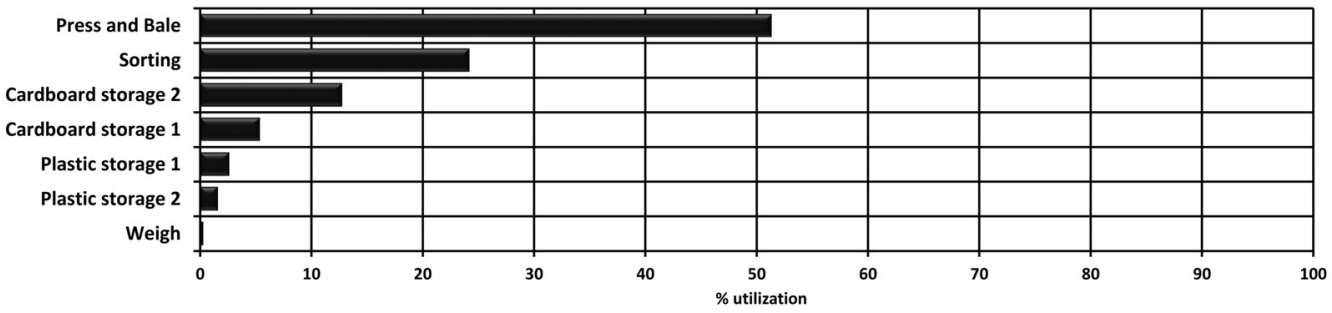

Figure 6 - Scenario A: Model Outputs.

By utilizing an operator and an assistant in the press, the time to carry out the activities of pressing and baling falls by approximately $50 \%$. There is a considerable reduction in the cardboard storage area's use due to the presses greater processing capacity. In turn, there was also an increase in the utilization of the baled cardboard storage area by about $13 \%$, due to the greater production of bales, which rose to an average of 11 bales per day. This represents a productivity jump of $83 \%$ when compared to the real scenario.

In scenario B, two presses are used with two operators without any assistants. Thus, the operator would be responsible for operating the equipment, loading the material in the press and wrapping the bale. Figure 7 presents the output data for Scenario B, which showed utilization of the two presses around $80 \%$ of the time (Press and Bale). The daily production attained a value of 12 bales, which represents double the bale production when compared with the real scenario, but has little variation when compared with scenario A.

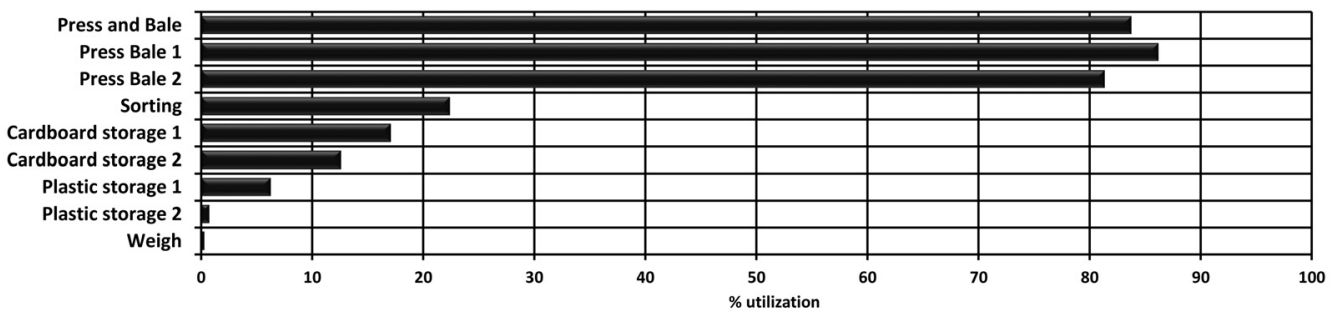

Figure 7 - Scenario B: Model Outputs.

Finally, the last scenario reflects a situation with two presses and two operators for each. In this experiment the bale production reached an average of 12 per day, equal to the previous scenario. However, this value is limited to the sorting processing capacity since the presses were utilized just $13 \%$ due to the lack of material to be processed. Figure 8 represents the utilization of each function in scenario C. This scenario also validates the study of other authors (Parreira, 2010), 
in which one of the principal bottlenecks related to the waste treatment was sorting the material which arrives at the shed mixed and dirty with organic material.

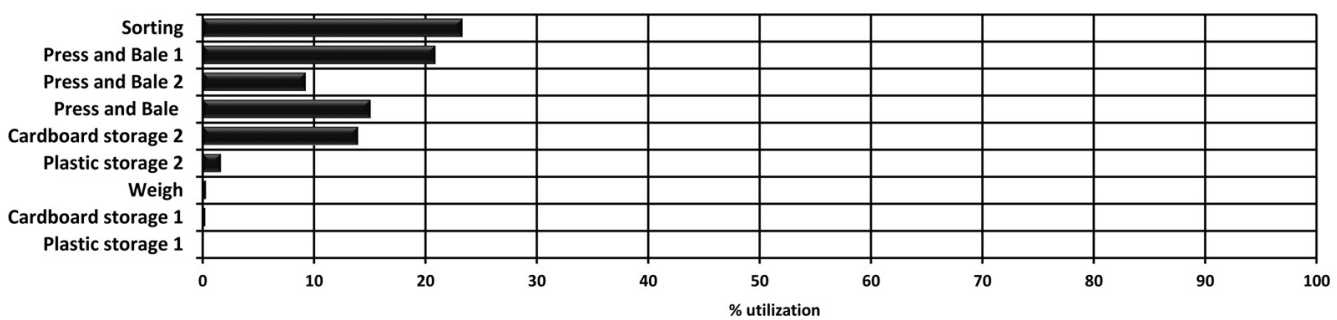

Figure 8 - Scenario C: Model outputs.

Considering the three plausible scenarios being executed, if there were no investments for improvements in the sorting phase, the acquisition of another press would not bring about many benefits for the process. The scenarios with two presses (scenarios B and C) would not present great increases in daily productivity due to the limitation in the quantity of material to be pressed. Thus, in order to effectively increase the association's daily productivity it becomes evident that a greater investment is needed in manual labor in order to improve sorting. Figure 9 shows a graph with each scenario, comparing utilization of the press and the number of bales produced.

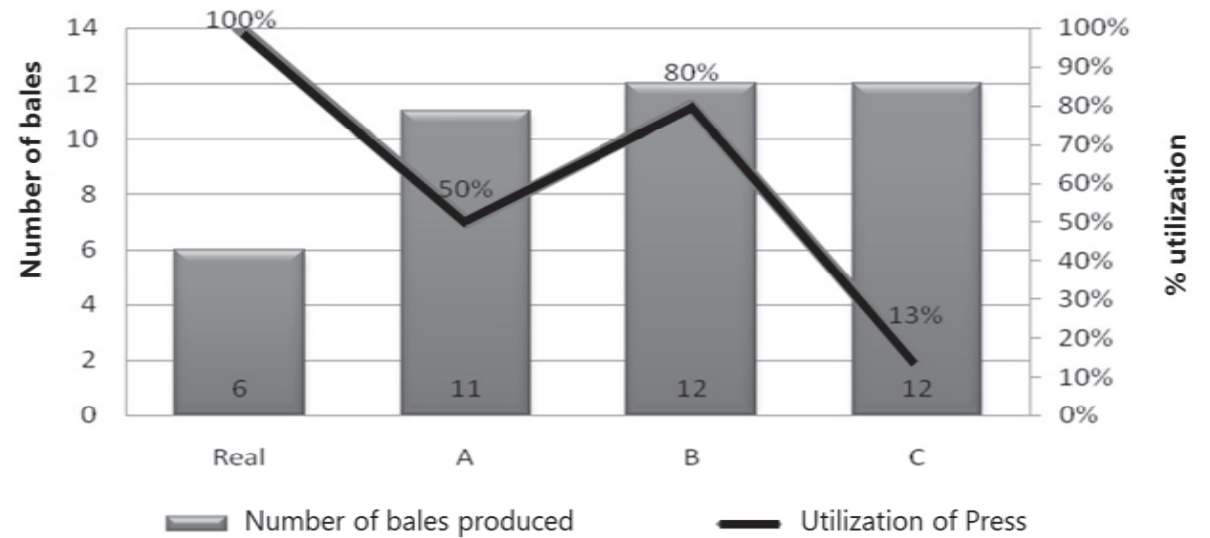

Figure 9 - Press Utilization and Number of Bales Produced in Each Scenario.

Scenario A requires the allocation of manual labor while scenario B requires the investment in new equipment. However, scenario B does not demonstrate a significant productivity increase. Scenario C does not initially show itself compatible with the association's reality, since the association would have to increase its materials gathering and/or donations in order to make the investment in equipment ( 2 presses) and manual labor ( 4 operators) worthwhile. Moreover, sorting time would have to be improved, which ended up becoming the new system's bottleneck. Thus, scenario A, which involves allocating one more operator in the pressing activity, is the 
most appropriate for the gatherers' association's reality. This would increase the press' productivity by $50 \%$ and enable increased productivity in the case of an increase in raw material.

\section{FINAL CONSIDERATIONS}

This work aimed to study a USW selection process by means of computational simulation. The project reached its global objective since the method utilized enabled the proposal of improvements for the Recyclable Materials Gatherers Association (ACIMAR) in Itajubá, Brazil.

Aside from proposing improvements, it also fell within the scope of this article to present the application of mapping and simulation techniques applied to a problem of USW treatment. It is well-known there are many hurdles for trash gathering associations, principally in terms of process management and administration. However, the research shows that it is possible to intervene and improve the recyclable treatment processes without harming the system's functioning.

The simulation developed enabled the perception of some particularities, such as the inadequate use of the press, proving to be the process's current bottleneck. However, with two presses and two operators, the new bottleneck would be the sorting activity, which would not be able to meet the demand necessary to feed the ideal press operation. The scenario that simulated two operators with a single press is the one which best adapts itself to the association's reality, as it would bring about a reduction in material processing time and a daily productivity increase of $85 \%$, thus leaving room for an increase in the amount of material collected or received from donations.

In conclusion, the research enabled the most detailed look yet at the association's USW treatment process and, as a product of the investigation, operational improvements were suggested. This should not, however, be the concluding study for this line of research, and for future opportunities, the authors recommend a standardization and rationalization of the activities performed by the gatherers and associates, aside from the possibility to use quality techniques, such as $5 \mathrm{~S}$ in order to redo the simulation project with the aim of refining its analysis.

\section{ACKNOWLEDGMENTS}

The authors would like to express their gratitude to the Brazilian agencies CNPq (National Council for Scientific and Technological Development), and FAPEMIG (Foundation for the Promotion of Science of the State of Minas Gerais), which have been supporting the efforts for the development of this work in different ways and periods.

\section{REFERENCES}

[1] Abdulmalek FA \& Rajgopal J. 2007. Analyzing the benefits of lean manufacturing and value stream mapping via simulation: a process sector case study. International Journal of Production Economics, 107(1): 223-236. 
[2] Abelpre - Brazilian Association of Public Cleaning and Special Waste. 2010. Overview of Solid Waste in Brazil - 2010. Available at: <http://www.abrelpe.org.br/panorama_ edicoes.cfm>. Accessed: June. 2011.

[3] Aguilar-Savén RS. 2004. Business process modeling: Review and framework. International Journal of Production Economics, 90(2): 129-149.

[4] Appelqvist P \& Lehtonen J-M. 2005. Combining optimization and simulation for steel production scheduling. Journal of Manufacturing Technology Management, 16(2): 197-210.

[5] Aquino IF, Castilho JR AB \& Pires TSL. 2009. Organizing a network of scavenger cooperatives in the reverse production chain of the metropolitan area of Florianopolis: an alternative for aggregating value. Gest. Prod. [online], 16(1): 15-24.

[6] Banks J, CARson Ii JS, Nelson BL \& NiCol DM. 2005. Discrete event system simulation. 4 ed. Prentice Hall. 624 p.

[7] BARI QH, HASSAN KM \& HAQUE ME. 2012. Solid waste recycling in Rajshahi city of Bangladesh. Waste Management, 32(11): 2029-2036, November 2012.

[8] Mazzer C \& CAVAlCANTe MDL. 2004. Introdução à Gestão Ambiental de Resíduos. Infarma. v. 16, n. 11-12, 2004. Available at: <http://www.cff.org.br/sistemas/geral/revista/pdf/77/i04aintroducao.pdf >. Accessed: Sept. 2013.

[9] D’Almeida MLO \& Vilhena A. 2000. Municipal Waste: Integrated Management Manual. 2 ed. São Paulo: IPT/CEMPRE. 370 p.

[10] East EW, Martinez JC \& Kirby JG. 2009. Discrete-event simulation based performance quantification of web-based and traditional bidder inquiry processes. Automation in Construction, 18(2): $109-117$.

[11] Genchev SE, Richey RG \& GABler CB. 2011. Evaluating reverse logistics programs: a suggested process formalization. International Journal of Logistics Management, 22(2): 242-263.

[12] Greasley A. 2006. Using process mapping and business process simulation to support a process based approach to change in a public sector organization. Technovation, 26: 95-103.

[13] Greasley A. 2003. Using business-process simulation within a business-process reengineering approach. Business Process Management Journal, 9(4): 408-420.

[14] Hojas baenas JM, de Castro R, Gomes Battistelle RA \& Gobbo Junior JA. 2011. A study of reverse logistics flow management in vehicle battery industries in the midwest of the state of São Paulo (Brazil). Journal of Cleaner Production, 19(2-3): 168-172.

[15] KLEIJNEN JPC. 1995. Verification and validation of simulation models. European Journal of Operational Research, 82(1): 145-162.

[16] LAMbert S, Riopel D \& ABDUl-KADER W. 2011. A reverse logistics decisions conceptual framework. Computers \& Industrial Engineering, 61: 561-581.

[17] Leal F, Costa RFS, Montevechi Jab, Almeida DA \& Marins FAS. 2011. A practical guide for operational validation of discrete simulation models. Pesquisa Operacional, 31(1): 57-77.

[18] Lobato KCD \& Lima JP. 2010. Characterization and evaluation of selection processes of urban solid waste through mapping technique. Eng. Sanit. Ambient., 15(4): 347-356. 
[19] Monteiro JHP \& Zveibil VZ. 2001. Handbook of Integrated Management of Solid Waste. Integrated Management of Solid Waste. 15 ed. Rio de Janeiro: IBAM - Brazilian Institute of Municipal Administration. 204 p.

[20] Montevechi JAB, Pinho AF, Leal F \& Marins FAS. 2007. Application of design of experiments on the simulation of a process in an automotive industry. Proceedings of the 2007 Winter Simulation Conference, Washington, DC, USA.

[21] Montevechi JAB, Costa RFS, Leal F \& Pinho AF. 2010. Economic Evaluation of Scenarios for Manufacturing Systems Using Discrete Event Simulation Based Experiments. Brazilian Journal of Operations \& Production Management, 7(1): 77-103.

[22] Moreira AMM \& GÜNTHER WMR. 2013. Assessment of medical waste management at a primary health-care center in São Paulo, Brazil. Waste Management, 33(1): 162-167, January 2013.

[23] NIST. 1993. Integration definition for functional modeling. Federal Information Processing Standards Publications, FIPS PUB 183.

[24] O'Kane JF, Spenceley JR \& TAYlor R. 2000. Simulation as an essential tool for advanced manufacturing technology problems. Journal of Materials Processing Technology, 107: 412-424.

[25] O’Leary PR \& Walsh PW. 1999. Decision Maker's Guide to Solid Waste Management, v.2. 2 ed. Washington DC: U.S. Environmental Protection Agency. 372 p.

[26] Oliveira RL, Lima RS \& Lima JP. 2013. Arc Routing Using a Geographic Information System: Application in Recyclable Materials Selective Collection. Advanced Materials Research (Online), v. 838-841, p. 2346-2353.

[27] PARREIRA GF. 2010. Waste collection solidarity: adding value by integrating to the recycling chain. Federal University of Minas Gerais. Belo Horizonte. Brazil. Available at: <http://www.bibliotecadigital.ufmg.br/dspace/handle/1843/NVEA-857HNR>. Accessed: Sept. 2013.

[28] Pirard F, IAssinoviki S \& Riane F. 2011. A simulation based approach for supply network control. Journal of Product Innovation Management, 49(24): 7205-7226.

[29] Polaz CNM \& TEIXEIRA BAN. 2009. Indicators of sustainability for municipal solid waste management: case study of the city of São Carlos (SP). Sanit. Ambient., 14(3): 411-420.

[30] RyAn J \& HEAVEy C. 2006. Process modeling for simulation. Computers in Industry, 57(5): 437450.

[31] SANCHEZ SM. 2007. Work smarter, not harder: guidelines for design simulation experiments. In: Proceedings of the winter simulation conference, Washington DC, p. 84-94.

[32] Sandanayake YG \& Oduoza CF. 2009. Dynamic simulation for performance optimization in just-in-time-enabled manufacturing processes. The International Journal of Advanced Manufacturing Technology, 42(3-4): 372-380.

[33] SARGent RG. 2004. Validation and verification of simulation models. In: Proceedings of the winter simulation conference, Washington DC.

[34] Simonetto EO \& Borenstein D. 2006. Operational management of solid waste selective collection - an approach using decision support system. Gest. Prod., 13(3): 449-461. 
[35] Singh RP, Singh P, Araujo ASF, Ibrahim MH \& Sulaiman O. 2011. Management of urban solid waste: Vermicomposting a sustainable option. Resources, Conservation and Recycling, 55(7): 719-729.

[36] TANSKAnEN J. 2000. Strategic planning of municipal solid waste management. Resources, Conservation and Recycling, 30: 111-133.

[37] Westarb Cruz JA, Quandt CO, Heitor Takashi Kato HT, Martins RRR \& Martins TS. 2013. How does the structure of social networks affect the performance of its actors? - A case study of recyclable materials collectors in the Brazilian context. Resources, Conservation and Recycling, 78: 36-46, September 2013. 